\title{
Raised by aliens: constant exposure to an invasive predator triggers morphological but not behavioural plasticity in a threatened species tadpoles
}

\author{
Andrea Melotto $\mathbb{D} \cdot$ Gentile Francesco Ficetola $\cdot$ Roberta Pennati • \\ Nicoletta Ancona $\cdot$ Raoul Manenti
}

Received: 9 November 2020/Accepted: 7 July 2021/Published online: 6 August 2021

(C) The Author(s) 2021

\begin{abstract}
During biotic invasions, native communities are abruptly exposed to novel and often severe selective pressures. The lack of common evolutionary history with invasive predators can hamper the expression of effective anti-predator responses in native prey, potentially accelerating population declines. Nonetheless, rapid adaptation and phenotypic plasticity may allow native species to cope with the new ecological pressures. We tested the hypothesis that phenotypic plasticity is fostered when facing invasive species and evaluated whether plasticity
\end{abstract}

Supplementary Information The online version contains supplementary material available at https://doi.org/10.1007/ s10530-021-02603-7.

A. Melotto $(\bowtie) \cdot$ G. F. Ficetola · R. Pennati .

N. Ancona - R. Manenti

Department of Environmental Science and Policy,

University of Milano, Milan, Italy

e-mail: mel8@hotmail.it

A. Melotto

Centre of Excellence for Invasion Biology, Department of

Botany and Zoology, Stellenbosch University,

Stellenbosch 7600, South Africa

G. F. Ficetola

Laboratoire D'Ecologie Alpine (LECA), CNRS, Univ.

Grenoble Alpes, Grenoble, France

N. Ancona

Curator At Acquario E Civica Stazione Idrobiologica Di

Milano, Milan, Italy offers a pool of variability that might help the fixation of adaptive phenotypes. We assessed behavioural and morphological trait variation in tadpoles of the Italian agile frog (Rana latastei) in response to the invasive crayfish predator, Procambarus clarkii, by rearing tadpoles under different predation-risk regimes: nonlethal crayfish presence and crayfish absence. After two-month rearing, crayfish-exposed tadpoles showed a plastic shift in their body shape and increased tail muscle size, while behavioural tests showed no effect of crayfish exposure on tadpole behaviour. Furthermore, multivariate analyses revealed weak divergence in morphology between invaded and uninvaded populations, while plasticity levels were similar between invaded and uninvaded populations. Even if tadpoles displayed multiple plastic responses to the novel predator, none of these shifts underwent fixation after crayfish arrival (10-15 years). Overall, these findings highlight that native prey can finely tune their responses to invasive predators through plasticity, but the adaptive value of these responses in whitstanding the novel selective pressures, and the longterm consequences they can entail remain to be ascertained.

Keywords Invasive species - Native amphibians . Phenotypic plasticity $\cdot$ Morphological defences . Behavioural defences 


\section{Background}

Phenotypic plasticity is among the most pervasive and fascinating products of natural selection, and can provide a given genotype the possibility to produce different phenotypic outcomes depending on the environmental conditions experienced (Pigliucci 2001). Plasticity is often favoured when the environmental context is heterogeneous, such as in environments where conditions are highly variable in time and / or space (Pigliucci 2001; Van Buskirk 2017; Reger et al. 2018, but see Leung et al. 2020). Under these circumstances, plasticity can allow species to adjust their responses and match challenges posed by changing selective pressures. Nevertheless, understanding the role of phenotypic plasticity is generally complex, because plasticity can occur in multiple traits (e.g., morphology, physiology and behaviour), can be expressed at different levels in different life history stages, and often trade-offs exist between modifications of one trait and its effects on the regulation of other traits (West-Eberhard 2003; Relyea 2007). Moreover, plastic responses to novel environmental pressures may not always be adaptive, as plastic shifts not matching the favoured phenotypic optimum can also occur (i.e., wrong sign plasticity, hyperplasticity, see Ghalambor et al. 2007; Stamp and Hadfield 2020). By interacting with genetic variation in determining phenotype expression, plasticity may also broaden the pool of variability on which natural selection acts, and eventually can favour refinement and fixation of traits showing particular adaptive value through genetic assimilation (Pigliucci et al. 2006; Levis et al. 2018; Levis and Pfennig 2019).

Plasticity can also represent a key factor for species facing the global changes that are affecting biodiversity. Due to anthropogenic transformation of earth's biosphere, species are increasingly exposed to new selective forces and unprecedented environmental variability (Bellard et al. 2016; Johnson and MunshiSouth 2017). Introduction of alien species is among the major changes induced by human activities and is a severe threat to biodiversity (Clavero and GarciaBerthou 2005; Bellard et al. 2016). The introduction of non-native species can abruptly impose strong selective pressures on native communities, as the lack of common evolutionary history can hamper the expression of adaptive responses towards the novel invaders (Salo et al. 2007; Sih et al. 2010). Understanding how native species cope with new selective pressures experienced during biotic invasions is an urgent challenge for conservation biology, and also represents an unprecedented opportunity to shed light on evolutionary mechanisms of adaptation (Mooney and Cleland 2001).

When a new predator invades a natural system, multiple outcomes are possible. In some cases, native prey fail to recognise it as a potential threat, or adopt ineffective anti-predator strategies that can lead to their rapid decline (Smith et al. 2008; Gomez-Mestre and Díaz-Paniagua 2011). Second, prey can respond through phenotypic plasticity (Nunes et al. 2014a; Saura-Mas and Benejam 2019). This requires novel predator recognition from native naïve prey, which can occur through several mechanisms (e.g., predator phylogenetic relatedness (Ferrari et al. 2007; Davis et al. 2012); generic predator cue recognition (Mathis and Vincent 2000; Cox and Lima 2006; Carthey and Blumstein 2018); neophobia (Brown and Chivers 2005; Rehage et al. 2009)). Third, selection can act on existing genetic variation, favouring rapid adaptations that can help withstanding the novel predator (Moore et al. 2004; Langkilde 2009; Bytheway and Banks 2019; Thawley et al. 2019; Melotto et al. 2020). Interactions between genotypic variation and environmental conditions are also possible, and interplays between plasticity and standing genetic variation may further complicate the responses of native species (Levis and Pfennig 2019; Noble et al. 2019). On the one hand, when the cost of plasticity is high and the expressed phenotypes match the favoured phenotypic optimum, natural selection can act on plastic adaptive phenotypes, refining and eventually fixing environmental-induced variation through genetic assimilation (canalization hypothesis; Pigliucci et al. 2006; Ghalambor et al. 2007; Levis et al. 2018). Under the canalization hypothesis, we expect evolution of lower plasticity in populations subjected to strong predatory pressure by the invader (Levis et al. 2018; Levis and Pfennig 2019). On the other hand, in some circumstances the most plastic individuals can be favoured by novel selective pressures, and selection can promote the plasticity of populations (increased plasticity hypothesis; Lande 2009; Chevin and Lande 2010; Manenti et al. 2013). Increased plasticity hypothesis predicts the evolution of stronger plastic response in invaded populations, particularly when environmental heterogeneity is strong (e.g., only part of the 
population is invaded), and / or when invasive predators are not the dominant selective force (Crispo 2008; Crispo and Chapman 2010).

Even though there is growing evidence that exposure to strong selective forces during biological invasions can determine rapid adaptive shifts (Phillips and Shine 2006; Langkilde 2009; Nunes et al. 2014b; Cattau et al. 2018; Thawley et al. 2019), knowledge of the mechanisms and dynamics leading these processes is far from exhaustive.

Among vertebrates, amphibians are highly sensitive to invasive predators, which often represent a primary cause of their decline (Kats and Ferrer 2003; Falaschi et al. 2019, 2020; Nunes et al. 2019). Nonetheless, amphibians can also show an impressive capacity to tune their responses to environmental variation through phenotypic plasticity (Relyea 2001; Warkentin 2011; Van Buskirk 2017; Levis and Pfennig 2019), which makes them an excellent model to study responses towards invasive species. During their larval stage, amphibians are generally subjected to heavy predation pressure (Wells 2007), and predation risk can trigger the expression of a wide variety of anti-predator strategies in amphibian larvae, which show a striking capability to modulate them through plasticity (Relyea 2007; Kishida et al. 2009; Hossie et al. 2017). Furthermore, larval amphibians can show rapid adaptations to novel predators (Kiesecker and Blaustein 1997; Moore et al. 2004; Nunes et al. 2014b), and this sometimes helps species coexistence (Moore et al. 2004). For instance, tadpoles of the frog Rana aurora evolved the ability to recognize invasive predators (Rana catesbeiana) in a few decades, increasing their refuge use in presence of bullfrog chemical cues (Kiesecker and Blaustein 1997), and adaptations can be even faster when predation pressures are particularly strong (Nunes et al. 2014b).

Here we assessed anti-predator responses in tadpoles of the Italian agile frog (Rana latastei) towards a recently introduced non-native predator, the invasive red swamp crayfish (Procambarus clarkii). This crayfish has been present in the study area since the early 2000s (Lo Parrino et al. 2020), and currently shows a patchy distribution, probably because of barriers and of complex dispersal mechanisms (Gherardi et al. 2000; Manenti et al. 2014). This study system includes both frog populations invaded by the crayfish in the past 10-15 years (approximatively 3-5 R. latastei generations (Guarino and Mazzotti 2001)), and uninvaded populations (Melotto et al. 2020). Tadpoles of this species are known to alter their morphology and behaviour in presence of native predators (Van Buskirk 2002; Scribano et al. 2020). Moreover, a recent study demonstrated that this frog accelerates development rates when exposed to invasive crayfish, and these shifts of development rate occur because of the joint effects of plasticity and local adaptation (Melotto et al. 2020). However, development rate is just one out of the many traits affecting survival of frog larvae. Behavioural and morphological parameters have a pivotal role for tadpole survival under heavy predatory pressure, but no study has assessed how plasticity and / or adaptation for these key traits can mediate responses to novel predators in tadpoles of $R$. latastei.

In the present study, we evaluated tadpole responses to the invasive crayfish by assessing a combination of behavioural and morphological traits that typically respond to predators and can be under strong selection in tadpoles (Van Buskirk and Arioli 2002; Relyea 2003; Kishida et al. 2010). We assessed behaviour at two distinct time points as traits can be expressed differently at different developmental stages. In particular, we evaluated (i) if non-lethal continuous exposure to the invasive predator during larval development triggers plastic variation in morphological or behavioural traits and (ii) if fixed divergence in tadpole traits exists between invaded and non-invaded populations. Finally (iii), by evaluating origin $\mathrm{x}$ treatment interaction we also assessed if invaded and uninvaded populations show different levels of plasticity, which would be expected under both the canalization and the increased plasticity hypotheses.

\section{Methods}

Study area and target species

The study area is located in Lombardy, NW Italy, between the Ticino and the Adda rivers (approx. $45.5 \mathrm{~N}, 9.2 \mathrm{E}$ ). This region is characterized by a dense hydrographic network, and hosts several populations of the Italian agile frog. This frog is endemic to the lowlands of Northern Italy and West Slovenia (Sillero et al. 2014), and is classified as vulnerable by the IUCN, with populations declining because of habitat 
loss, fragmentation, and invasive species (Sindaco et al. 2009). The American red swamp crayfish is among the most threatening invasive alien predators at the global scale (Gherardi 2006; Nentwig et al. 2018), and it preys upon both amphibian eggs and larvae and has been associated with several cases of amphibian declines (Rodríguez et al. 2005; Cruz et al. 2008; Ficetola et al. 2011; Falaschi et al. 2021). The crayfish was introduced in the study area in the early 2000's (Lo Parrino et al. 2020) and is now widespread, causing decrease in abundance of several amphibian species, including the Italian agile frog (Ficetola et al. 2011; Manenti et al. 2020). Recent analyses confirmed that $R$. latastei tadpoles can recognize the American red swamp crayfish as a predator and respond to its presence by decreasing their development time, a typical anti-predatory reponse of amphibians (Melotto et al. 2020).

\section{Collection and rearing conditions}

We collected egg clutches of the Italian agile frog in early spring (March) 2017, immediately after laying. We selected six $R$. latastei populations breeding in sites invaded by the $P$. clarkii (in the past 10-15 years), and three populations breeding in sites where the crayfish is absent. The broad invasive range of the crayfish limited the number of uninvaded populations. In total, we collected 36 clutches from invaded populations and 18 from uninvaded populations (3-11 clutches per population). The individuals analysed here are the same of a previous study analysing shifts in development time in response to the crayfish (Melotto et al. 2020). During sampling, we carefully removed a small portion from each clutch. Each clutch sample was individually placed in tanks filled with decanted tap water and maintained under outdoor conditions in a shaded area to mimick natural canopy cover. After hatching, tadpoles were maintained under the same conditions until reaching Gosner's stage 25 (Gosner 1960). At this stage, we randomly selected six tadpoles from each clutch and divided them in two groups of three individuals (hereafter called triads). Selected individuals $(\mathrm{N}=324)$ were dorsally photographed on graph paper to measure total length (from the tip of the snout to the tail tip) using the ImageJ software (Schneider et al. 2012). After measurement, the two triads from each egg clutch were assigned to a different rearing
Fig. 1 Experimental plan, sampling and rearing conditions (A). We collected 54 egg clutches from nine Rana latastei populations (six invaded by the American crayfish and three uninvaded). At Gosner's stage 25, six tadpoles from each egg clutch $(\mathrm{N}=324)$ were split into two triads and assigned at two rearing treatments: non-lethal exposure to the crayfish vs crayfish absence. Tadpole morphological traits (B) were measured after two months: total length, body depth (BD), body width (BW), body length (BL), tail depth (TD), tail length (TL), tail muscle depth (TMD) and tail muscle width (TMW). Tadpole activity (C) was assessed during two behavioural sessions after one and two months of rearing by recording ten parameters (distance moved; crayfish avoidance; sibling aggregation; maximum speed; mean speed; maximum movement length; mean movement length; maximum movement duration; mean movement duration). All behavioural traits were calculated as the mean score of tadpoles in each triad

treatment: non-lethal exposure to $P$. clarkii, and absence of the invasive crayfish during rearing (Fig. 1A; see also Melotto et al. 2020). During rearing, tadpoles were hosted in six $70 \times 48 \mathrm{~cm}$ plastic tanks (three for each rearing treatment; hereafter called blocks) filled with 341 of aged tap water. Each block contained 18 triads, which were separately housed in 0.81 containers. In the crayfish-exposure treatment, an adult $P$. clarkii was enclosed in the central section of the tank $(24 \times 28 \mathrm{~cm})$, which was surrounded by tadpole containers; a thin plastic net $(\varnothing=0.2 \mathrm{~cm})$ separated triads from the container with the crayfish so that tadpoles were exposed to both visual and chemical cues of the crayfish, but any predation attempt was prevented. In blocks where tadpoles were not exposed to crayfish, conditions were identical except for the absence of the crayfish. Tadpoles were exposed to natural diel temperature fluctuations, with an average temperature of $18.2 \pm 2.2{ }^{\circ} \mathrm{C}$. During rearing, water was changed weekly and both tadpoles and crayfishes were fed with fish food and rabbit pellets, providing new food items every third day. We performed two sessions of behavioural tests (after one and two months of rearing), while the measurement of morphological traits was only performed after two months of rearing. Overall, 235 and 193 tadpoles survived to the first and the second month of rearing, respectively; survival rate was similar to previous laboratory studies performed on this species (Ficetola and De Bernardi 2005; Ficetola et al. 2007). Tadpole survival was similar across treatments and tadpole origin (Melotto et al. 2020). 
(A)

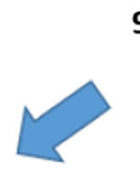

6 Crayfish-invaded
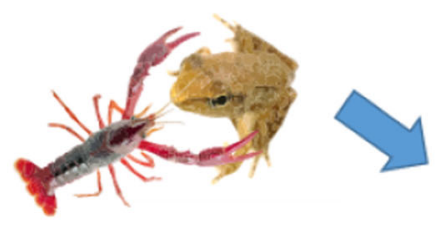

54 egg clutches

\section{Rana latastei \\ populations}
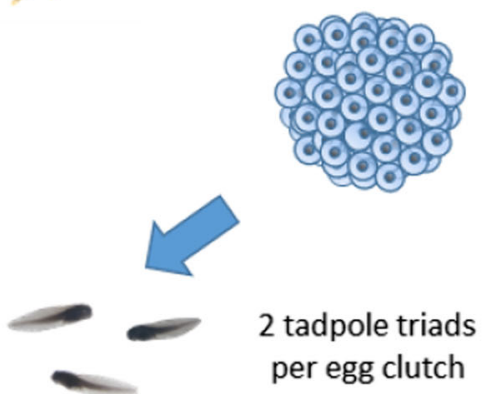

2 tadpole triads
per egg clutch

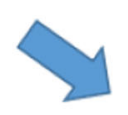

$3 x$

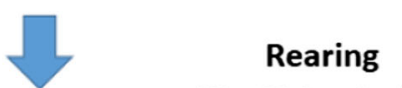

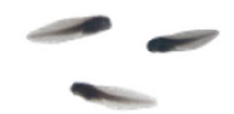

( $\mathrm{N}=324$ tadpoles)

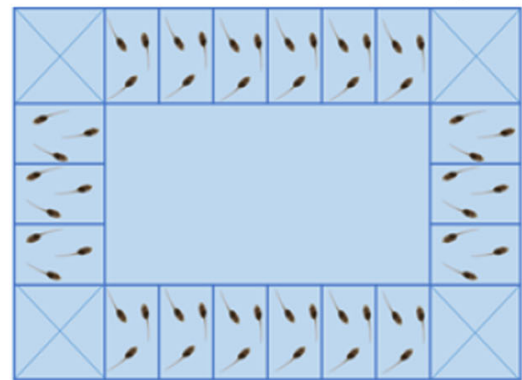

Crayfish absence

(B)

Tadpole morphology

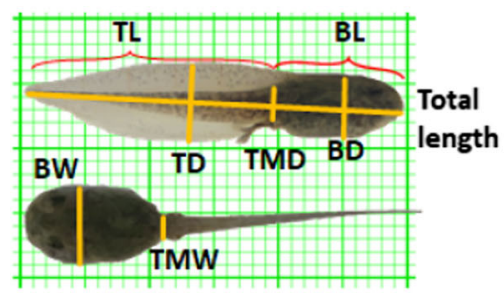

After two months of rearing

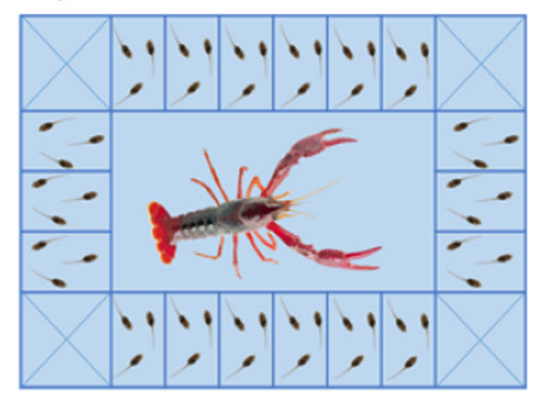

Non-lethal crayfish presence

(C)

Tadpole activity

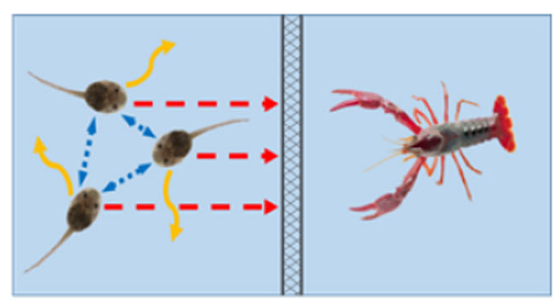

After one and two months of rearing 
(A)

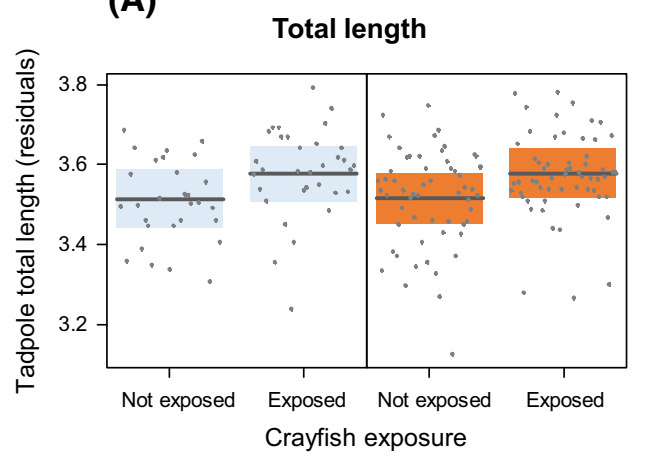

(C)

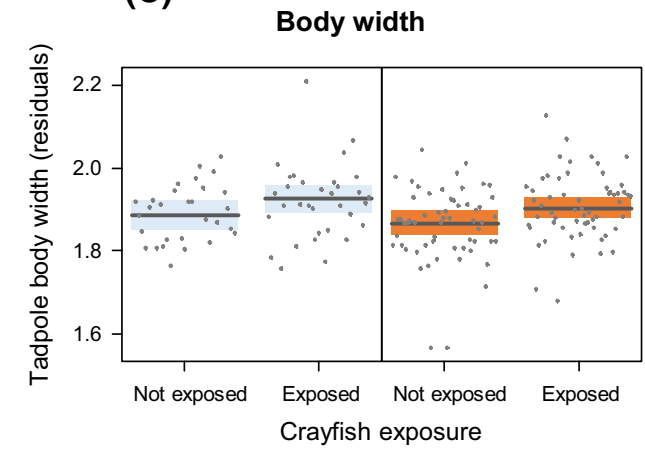

(E)

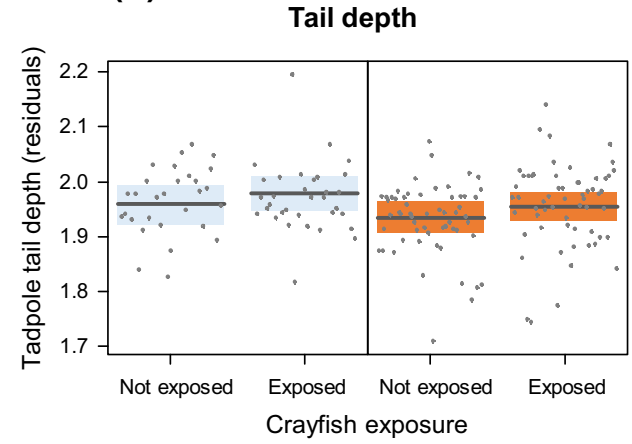

(G)

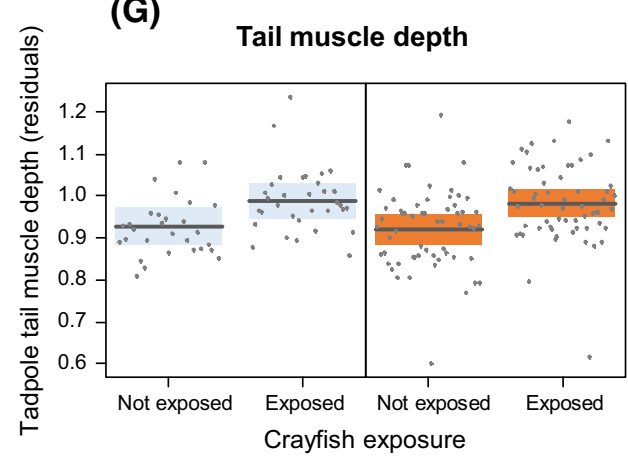

(B)

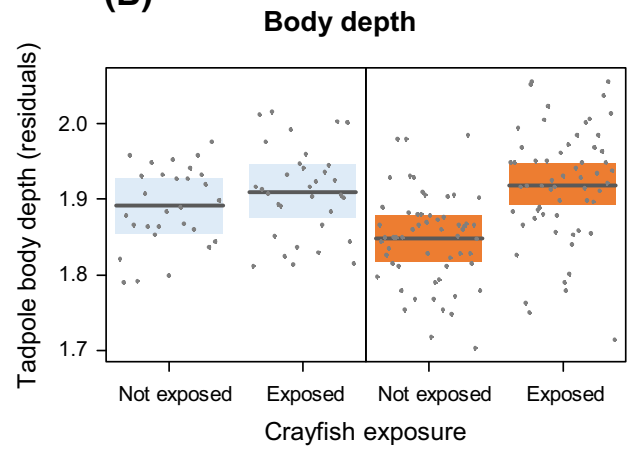

(D)

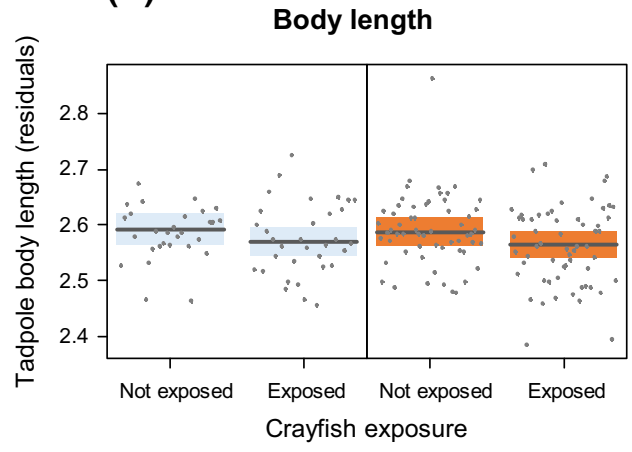

(F)

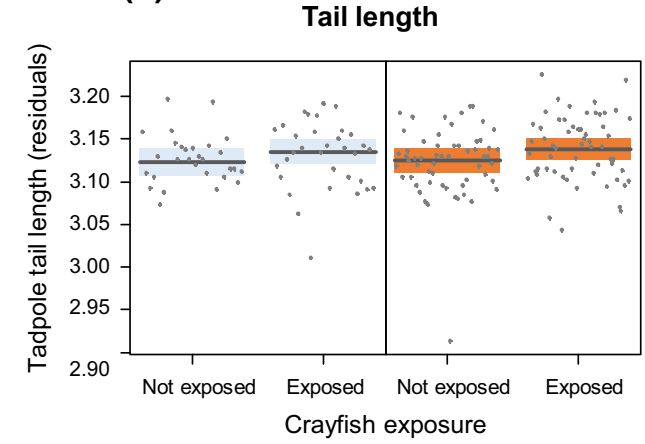

(H)

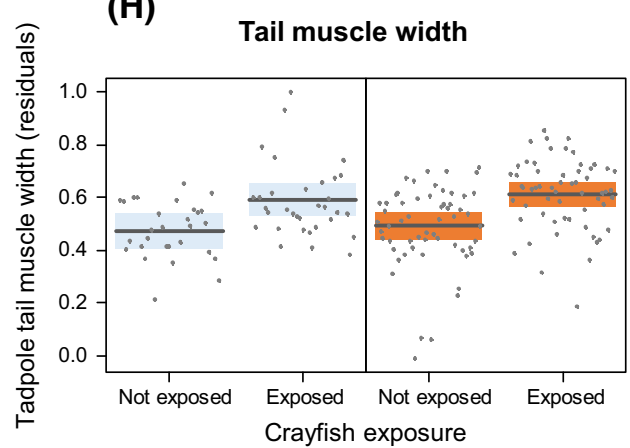

Crayfish-invaded populations

Uninvaded populations 
४Fig. 2 Effect of origin and treatment on tadpole morphological traits. Partial residual regression plots showing the relative influence of origin (crayfish invaded vs uninvaded populations) and treatment (exposed vs not exposed to crayfish) on eight traits (from $\mathbf{A}$ to $\mathbf{H}$ ): total length, body depth, body width, body length, tail depth, tail length, tail muscle depth and tail muscle width. Orange boxes represents invaded populations; light blue boxes stand for uninvaded populations. Shaded areas are $95 \%$ confidence bands

\section{Morphological traits}

After two months of rearing $(67.5 \pm 0.1$ days after attaining stage 25), we measured morphological features of surviving tadpoles. Tadpoles were briefly transferred in small transparent boxes and photographed with plastic graph paper. Each tadpole was photographed both dorsally and laterally and we used ImageJ (Schneider et al. 2012) to measure eight morphological traits (Fig. 1B): total length (from snout tip to tail tip), body depth, body length, body width, tail depth, tail length, tail muscle depth and tail muscle width (Relyea 2001). Body and tail depth and body width were measured at their maximum depth and width, while muscle width and muscle depth were measured at the basis of the tail. Fourteen tadpoles were excluded from the analyses because of insufficient quality of pictures; in total, morphological traits were available for 179 tadpoles.

Tadpole activity and space use

During rearing, we performed two experimental sessions to record tadpole activity and assess antipredator behavioural responses. This allowed us investigating potential variation of their behaviour across considerably different development stages. The first session took place after approx. four weeks of rearing (28.9 \pm 0.2 days from stage 25 , Gosner's stage 27-30) and included 235 tadpoles from 90 triads ( $\mathrm{N}=172$ tests). The second session was performed approx. two months after stage 25 (67.5 \pm 0.1 days, Gosner's stage 35-40; immediately before morphological measurements) on 186 individuals from 82 triads $(\mathrm{N}=154$ tests); data for seven individuals (three triads) are missing as camera failed to record their videos. During behavioural sessions, baseline tadpole activity (i.e., movements and use of the space) was recorded in the rearing tank, maintaining the same predator exposure condition, by placing a Canon SX40 HS camera above the container of each triad. Each video-recording consisted of a five-minute trial. The first minute of all video-recordings was excluded from analyses, as preliminary tests showed that tadpoles have an acclimation time of approximately one minute after camera positioning by the operator. All videos were recorded on the same day between 9 a.m. and 5 p.m., with two trials per triad (one in the morning and one in the afternoon) during each session. Tapdoles were fed two days before video-recording, and then fed at the end of the video session. The day before tests, we removed from triad containers all food traces to avoid introducing potential bias on tadpole behaviour and to improve their visibility in videos. Videos were analysed with the video-tracking software idTracker. This software can distinguish the shape of the focal animals on the basis of both their size and their contrast with the background, recording their displacements in the experimental arena (the $7 \times 11.5 \mathrm{~cm}$ triad container in this study) (PérezEscudero et al. 2014). idTracker returns a set of coordinates corresponding to the position of each focal animal in the arena during each frame of the video. Basing on this set of coordinates, we reconstructed the trajectories of individuals in the $\mathrm{R}$ environment ( $\mathrm{R}$ 2019) and recorded ten behavioural parameters (Fig. 1C) that are commonly involved in the antipredator response: total distance covered by tadpoles (Distance moved), the mean distance between the tadpole and the net separating tadpoles from the crayfish (Avoidance) and the mean distance among tadpoles (Aggregation), the number of movements performed by tadpoles ( $N$ movements), along with mean and maximum movement length, duration and speed. Activity reduction and responses maximising predator avoidance are common anti-predator behaviours, however complex trade-offs with other fitnessrelated activities (i.e., foraging) exist and prey have to finely tune their behavioural response according to risk exposure (Relyea 2007; Ferrari et al. 2009; Melotto et al. 2019). Thus, we included an extensive panel of parameters describing tadpoles activity. Aggregation was only calculated on triads with more than one surviving individual (respectively $\mathrm{N}=86$ and $\mathrm{N}=72$ triads after the first and the second month). Correlations among behavioural traits are shown in supplementary material (see Table S1). All 
behavioural traits were calculated as the mean score of tadpoles in each triad.

\section{Statistical analysis}

The analyses of both morphological and behavioural traits were performed combining a multivariate and an univariate approach. For morphological traits, we first run a Linear Mixed Model (LMM) to assess variation of body size (i.e., total length). This LMM included treatment (exposed vs not exposed to crayfish during rearing) and origin (crayfish-invaded populations vs uninvaded populations) as fixed factors. Moreover, we included the number of surviving siblings in the triad (one to three), and tadpole starting size as covariates, while population identity, egg-clutch identity and rearing block were random factors. The number of siblings was included to consider potential competition (Wells 2007), while tadpole starting size was intended to take into account potential non-genetic maternal effects, since it is a good indicator of the amount of yolk provided by the mother to the eggs (Kaplan 1998). The remaining seven traits were strongly correlated to body size, thus we run a multivariate model (MANOVA) considering all the morphological traits, except total length, as response variables. The MANOVA included the same fixed and random effects of the LMM on body size, and also included body size as covariate. An interaction between origin and treatment was intended to test hypotheses on potential variation of phenotypic plasticity. Preliminary analyses showed no significant effect of origin or crayfish exposure on total length, suggesting that differences in slope of the growth trajectory were unlikely. The MANOVA was followed by separate LMMs with each morphological trait as unique response variable to explore in detail the effect of fixed factors on each single trait. LMMs included the same random factors of MANOVAs, as well as all the fixed effects that were significant in the multivariate analysis. In all models, prior to performing analyses, morphological traits were log transformed to the improve normality of residuals.

We used a similar MANOVA model structure to analyse behavioural variation. The ten behavioural parameters were the response variables, while fixed factors included treatment, origin, and number of surviving siblings as a covariate, since the presence of conspecifics can affect tadpole activity (Wells 2007).
Test replicate (first vs second replicate) and period (one month vs two months of rearing) were included as additional fixed factors to take into account behavioural differences between subsequent tests or different development stages, respectively. Preliminary analyses considering the two periods separately provided identical results. Size was highly correlated with test period, thus tadpole length was not included as covariate in behavioural analyses. Behavioural traits analysed in the models were square-root transformed to improve normality of residuals. The MANOVA was then followed by LMMs assessing the effect of fixed factors that were significant in the multivariate tests.

Significance of fixed factors in MANOVAs was assessed using Pillai's trace. All analyses were performed in the $\mathrm{R}$ environment ( $\mathrm{R}$ version 3.6.0), using packages lmerTest, lme4 and MuMIn; partial regression plots were built using the visreg package.

\section{Ethical statement}

The present study was performed under the authorization of Italian Ministry for Environment (DPN/17391 and Prot. N. 3383/T-A31). After the end of experiments, all the individuals were treated with Virkon $\mathrm{S}$ to prevent risks of disease spreading (Jussila et al. 2014; Bosch et al. 2015) and then released in their site of origin.

\section{Results}

Morphological traits of tadpoles

Tadpole total length was not significantly affected by exposure to the crayfish or origin in two-months old tadpoles (Table 1A, Fig. 2A), while it was positively related to starting size, and decreased significantly in triads with more surviving siblings (Table 1A).

Results of the multivariate analysis on the remaining morphological traits showed that both crayfish exposure $(P<0.001)$ and origin from invaded populations $(P=0.012)$ had a significant role in shaping tadpole morphology (Table 1B). Crayfish exposure showed higher effect size than origin. Moreover, all the traits were positively related to tadpole total length $(P<0.001)$, while we detected no effect of the number of siblings $(P=0.258)$ or the starting size 
Table 1 Influence of the fixed factors on tadpole morphological traits

\begin{tabular}{|c|c|c|c|c|c|c|c|c|c|}
\hline \multirow[t]{2}{*}{ A) } & \multicolumn{9}{|c|}{ Total length model } \\
\hline & Fixed factor & $B$ & df & $\mathrm{F}$ & $\mathrm{P}$ & $\begin{array}{l}\text { Fisher's } \\
\mathrm{z}\end{array}$ & $95 \% \mathrm{CIs}$ & & \\
\hline & Origin & 0.062 & $1,3.8$ & $<0.01$ & 0.975 & 0.02 & -3.12 & - & 3.16 \\
\hline & Treatment & 0.001 & $1,3.5$ & 2.69 & 0.187 & 0.71 & -2.23 & - & 3.66 \\
\hline & $\begin{array}{l}\text { Starting } \\
\text { size }\end{array}$ & 0.212 & $1,47.2$ & 6.72 & 0.013 & 0.37 & 0.07 & - & 0.66 \\
\hline & N siblings & -0.067 & $1,116.7$ & 15.62 & $<0.001$ & 0.36 & 0.17 & - & 0.54 \\
\hline \multirow[t]{8}{*}{ B) } & \multicolumn{9}{|c|}{ Multivariate model for morphological traits } \\
\hline & \multicolumn{2}{|l|}{ Fixed factor } & df & $\mathrm{F}$ & $\mathrm{P}$ & $\begin{array}{l}\text { Fisher's } \\
\mathrm{z}\end{array}$ & \multicolumn{2}{|l|}{$95 \%$ CIs } & \\
\hline & \multicolumn{2}{|l|}{ Origin } & 7,163 & 2.69 & 0.012 & 0.13 & $-\mathbf{0 . 0 3}$ & - & 0.28 \\
\hline & \multicolumn{2}{|l|}{ Treatment } & 7,163 & 4.49 & $<0.001$ & 0.16 & 0.01 & - & 0.31 \\
\hline & \multicolumn{2}{|l|}{ Total length } & 7,163 & $33,385.69$ & $<0.001$ & 3.33 & 3.18 & - & 3.49 \\
\hline & \multicolumn{2}{|l|}{ Starting size } & 7,163 & 0.51 & 0.829 & 0.05 & -0.10 & - & 0.21 \\
\hline & \multicolumn{2}{|l|}{$\mathrm{N}$ siblings } & 7,163 & 1.29 & 0.258 & 0.09 & -0.07 & - & 0.24 \\
\hline & \multicolumn{2}{|c|}{ Origin $\times$ Treatment } & 7,163 & 1.43 & 0.196 & 0.09 & -0.06 & - & 0.24 \\
\hline
\end{tabular}

C) Univariate models for morphological traits

\begin{tabular}{|c|c|c|c|c|c|c|c|c|c|}
\hline & & & & & & & & & \\
\hline & Fixed factor & $B$ & df & $\mathrm{F}$ & $\mathrm{P}$ & Fisher's z & $95 \%$ Cis & & \\
\hline \multirow[t]{3}{*}{ Body depth } & Origin & -0.013 & $1,39.3$ & 0.80 & 0.378 & 0.14 & -0.19 & - & 0.47 \\
\hline & Treatment & 0.052 & $1,3.3$ & 14.35 & 0.027 & 1.36 & -1.96 & - & 4.68 \\
\hline & Total length & 0.624 & $1,172.3$ & 209.76 & $<0.001$ & 0.95 & 0.80 & - & 1.10 \\
\hline \multirow[t]{3}{*}{ Body width } & Origin & -0.018 & $1,4.4$ & 1.00 & 0.368 & 0.42 & -1.49 & - & 2.33 \\
\hline & Treatment & 0.030 & $1,165.9$ & 5.25 & 0.023 & 0.18 & 0.02 & - & 0.33 \\
\hline & Total length & 0.741 & 1, 166.0 & 219.95 & $<0.001$ & 0.98 & 0.83 & - & 1.14 \\
\hline \multirow[t]{3}{*}{ Body length } & Origin & -0.004 & $1,174.0$ & 0.12 & 0.729 & 0.03 & -0.12 & - & 0.18 \\
\hline & Treatment & -0.020 & $1,3.83$ & 1.46 & 0.300 & 0.52 & -1.91 & - & 2.96 \\
\hline & Total length & 0.728 & $1,173.8$ & 373.60 & $<0.001$ & 1.17 & 1.02 & - & 1.32 \\
\hline \multirow[t]{3}{*}{ Tail depth } & Origin & -0.021 & $1,41.5$ & 1.52 & 0.223 & 0.19 & -0.13 & - & 0.51 \\
\hline & Treatment & 0.018 & $1,156.9$ & 2.33 & 0.129 & 0.12 & -0.04 & - & 0.28 \\
\hline & Total length & 0.867 & $1,173.5$ & 353. 90 & $<0.001$ & 1.15 & 1.00 & - & 1.30 \\
\hline \multirow[t]{3}{*}{ Tail length } & Origin & 0.002 & $1,174.3$ & 0.11 & 0.739 & 0.03 & -0.13 & - & 0.18 \\
\hline & Treatment & 0.010 & $1,3.8$ & 1.29 & 0.321 & 0.50 & -1.95 & - & 2.94 \\
\hline & Total length & 1.161 & $1,172.2$ & 2670.73 & $<0.001$ & 2.08 & 1.93 & - & 2.23 \\
\hline \multirow[t]{3}{*}{ Tail muscle depth } & Origin & -0.002 & $1,4.2$ & 0.01 & 0.937 & 0.04 & -2.03 & - & 2.10 \\
\hline & Treatment & 0.054 & $1,162.3$ & 16.27 & $<0.001$ & 0.31 & 0.15 & - & 0.47 \\
\hline & Total length & 0.874 & 1, 163.0 & 295.15 & $<0.001$ & 1.10 & 0.95 & - & 1.26 \\
\hline
\end{tabular}


Table 1 continued

\begin{tabular}{llllllllll}
\hline C) & \multicolumn{4}{c}{ Univariate models for morphological traits } & & \\
\cline { 3 - 9 } & & Fixed factor & $B$ & df & F & P & Fisher's z & $95 \%$ Cis \\
\hline \multirow{2}{*}{ Tail muscle width } & Origin & 0.020 & $1,6.5$ & 0.38 & 0.559 & 0.22 & -0.96 & - & 1.41 \\
& Treatment & $\mathbf{0 . 1 1 1}$ & $\mathbf{1 , 1 6 7 . 3}$ & $\mathbf{2 6 . 6 7}$ & $<\mathbf{0 . 0 0 1}$ & $\mathbf{0 . 3 9}$ & $\mathbf{0 . 2 3}$ & - & $\mathbf{0 . 5 4}$ \\
& Total length & $\mathbf{1 . 0 8 2}$ & $\mathbf{1 , 1 5 7 . 4}$ & $\mathbf{1 8 4 . 1 1}$ & $<\mathbf{0 . 0 0 1}$ & $\mathbf{0 . 9 4}$ & $\mathbf{0 . 7 8}$ & - & $\mathbf{1 . 0 9}$ \\
\hline
\end{tabular}

Results of univariate model on tadpole length (LMMs; A), and multivariate (MANOVA; B) and subsequent univariate models on the other morphological traits (LMMs; C) showing the effect of origin (invaded vs uninvaded populations) and treatment (exposed vs not exposed to crayfish). Tadpole total length was tested separately including the number of surviving siblings per triad, and tadpole starting size as covariates. Multivariate model included as dependent variable all the morphological traits (except from tadpole total length), while the fixed factors were the same used in total length model, with tadpole total length as an additional covariate. Subsequent univariate models for all the remnant morphological traits, included all the fixed factors that resulted significant in the multivariate models (see methods). All models included population identity, egg-clutch identity and rearing block as random factors. Degrees of freedom, test coefficient and effect size (Fisher's z), together with its $95 \%$ confidence intervals, are reported for all models, while model estimates $(B)$ are also reported for univariate ones. Significant results are in bold

$(P=0.829)$. The interaction between crayfish exposure and origin was not significant $(P=0.196)$.

Univariate linear mixed models revealed that treatment had a significant effect on multiple morphological traits (Table 1C); the impact of crayfish exposure was particularly evident for traits describing tail muscle. Specifically, tadpoles exposed to the crayfish showed a significant increase in relative body depth (Fig. 2B), body width (Fig. 2C), tail muscle depth (Fig. 2G) and tail muscle width (Fig. 2H). Instead, univariate tests did not detect any significant difference between invaded and uninvaded populations (all $P>0.2$; Table 1C, Fig. 2A-G).
Tadpoles activity and space use

Multivariate analysis showed that neither origin $(P=0.286)$, nor crayfish exposure during rearing $(P=0.550)$, nor the interaction between origin and exposure $(P=0.089)$ significantly affected tadpole behaviour (Table 2). Instead, period and number of siblings and test replicate showed a significant effect on tadpole activity.

Univariate models revealed that, at the second month, tadpoles significantly increased their activity at all the behavioural traits (Table S2). Finally, the number of siblings was positively associated to mean and maximum movement length (both $P<0.01$ ), maximum movement duration $(P=0.007)$, and to

Table 2 Multivariate analysis assessing the effect of origin (crayfish invaded vs uninvaded populations) and treatment (exposed vs not exposed to crayfish) on ten behavioural traits (see methods)

\begin{tabular}{llrrrrr}
\hline \multicolumn{2}{l}{ Multivariate models for behavioural traits } & & & & \\
\hline Fixed factor & df & F & P & Fisher's z & $95 \%$ CIs \\
\hline Origin & 10,282 & 1.21 & 0.286 & 0.06 & -0.05 & - \\
Treatment & 10,282 & 0.88 & 0.550 & 0.05 & -0.06 & - \\
N siblings & $\mathbf{1 0 , 2 8 2}$ & $\mathbf{3 . 5 4}$ & $<\mathbf{0 . 0 0 1}$ & $\mathbf{0 . 1 1}$ & $-\mathbf{0 . 0 1}$ & - \\
Period & $\mathbf{1 0 , 2 8 2}$ & $\mathbf{2 4 . 9 5}$ & $\mathbf{< . 0 0 1}$ & $\mathbf{0 . 2 9}$ & $\mathbf{0 . 1 7}$ & - \\
Test replicate & $\mathbf{1 0 , 2 8 2}$ & $\mathbf{2 . 3 8}$ & $\mathbf{0 . 0 1 0}$ & $\mathbf{0 . 0 9}$ & $\mathbf{0 . 0 2}$ & - \\
Origin x Treatment & 10,282 & 1.66 & 0.089 & 0.08 & $\mathbf{0 . 4 0}$ \\
\hline
\end{tabular}

All values of behavioural traits are the mean score of siblings composing the triad. The number of surviving siblings per triad, period (one month or two months of rearing) and test replicate (first or second replicate) were included in the model as additional covariates, while population identity, egg-clutch identity and rearing block were random factors. Degrees of freedom, test coefficient and effect size (Fisher's z), together with its upper and lower intervals, are reported. Significant results are in bold. Univariate tests for variables with significant multivariate effects are shown in Table S2 
avoidance $(P=0.019)$, revealing a general increase in tadpole activity when more conspecifics where present (Table S2). Mean values, standard error and the range (minimum-maximum value) of all behavioural parameters are reported as supplementary material (see Supplementary Table S3).

\section{Discussion}

Amphibian larvae can respond to alien predators by activating a suite of trait modifications through phenotypic plasticity. Rana latastei tadpoles showed the capacity to finely tune their phenotypic response when exposed to the invasive crayfish during development, as its presence fostered the plastic modification of multiple morphological traits, while we did not detect any behavioural response. Overall, plastic responses to the crayfish occurrence were much stronger than differences between invaded and uninvaded populations, suggesting that plasticity currently is the strongest response to this invasive species.

Tadpoles reared with the crayfish showed clear morphological plasticity in multiple body features, such as increased muscle depth and width of tail muscle. The plastic response was evident in four out of eight morphological traits (Table 1; Fig. 2B-C, G-H), suggesting that tadpoles are able to express complex and generalized modifications when invasive predators are present. Increased tail muscle is a typical plastic response observed when tadpoles are exposed to native predators (Relyea 2001; Van Buskirk 2009), which is associated to faster swimming performance, and can improve the ability to escape predators (Dayton et al. 2005; Pease and Wayne 2014). Such a modification in tail shape could in priciple also improve tadpole survival to crayfish predation in the invaded wetlands and potentially enhance the capacity of this species to withstand this invasive predator. However, our study did not directly assess the survival of induced phenotypes to crayfish predation, and the actual adaptive value of these responses remains to be tested. Furthermore, in crayfish-exposed tadpoles we observed a slight increase in relative body dimension (relative body depth and width). These plastic modifications have been reported by some studies assessing responses to native and invasive predators, still are not consistently observed across species, suggesting that they can provide a complex or context-dependent advantages (Van Buskirk 2009; Nunes et al. 2014a). For instance, earlier metamorphosis observed in tadpoles reared with the crayfish, was accompanied by a slight increase in growth rate, likely because of compensatory growth mechanisms (Melotto et al. 2020). The deeper and wider body observed in crayfish-exposed tadpoles after two months of rearing might thus be related to the overall plastic shift in growth trajectory associated to faster development.

Conversely, morphological differences between invaded and uninvaded populations were weak, with very limited effect sizes (Table 2) and only detectable through multivariate analyses. This is likely due to the increased statistical power of multivariate models when analysing highly correlated dependent variables (as morphological traits; Field et al. 2012) which allow to detect even very weak effects, that cannot be identified by univariate analyses. Amphibian larvae can have a remarkable ability to adapt under strong selective pressure posed by invasive species and other global change stressors (Moore et al. 2004; Nunes et al. 2019; Falaschi et al. 2020), and invaded populations of this species evolved a faster intrinsic development time, probably as this adaptative shift reduces tadpole exposure to predators (Melotto et al. 2020). Several studies have shown the rapid evolution of morphological modifications in response to invasive predators (e.g., Moore et al. 2004; Nunes et al. 2014b). In our study case invaded populations only showed weak evidence for differences in tadpole morphology, thus providing little support to the local adaptation or canalization hypotheses, at least for the traits here measured. The lack of behavioural differences between invaded and not invaded populations, and the feeble effects detected for morphology, could occur because of multiple reasons. First, it is possible that tadpole tail morphology confers a limited advantage when facing the alien crayfish, and this seems to be partly supported by the general mismatch between the signs of plastic shifts and constitutive differences (see model estimates in Table 1 and Fig. 2). Second, the study populations have only been recently invaded (approx. 3-5 generations ago), thus more time could be required for evolutionary shifts. Furthermore, the Italian agile frog is a threatened species with high inbreeding and low genetic diversity (Garner et al. 2004; Ficetola et al. 2007), and this can limit the adaptive potential of populations (Frankham et al. 2004), at least for the traits considered here. Finally, 
modulation of morphological traits constitutes just a small part of the tadpole inducible defences, while tadpole survival and individual fitness can be influenced by the complex interplay between morphology, environmental variation, and other traits. For instance, the development acceleration observed in populations invaded by the crayfish could confer selective advantages withstanding crayfish predation, thus overcoming the benefits of further shifts in morphology, or constrain morphological trait shifts, or perhaps this trait is characterized by very high evolvability. Thus, the prediction of which traits are most likely to evolve in response to invasive species, in which direction and within which time frames is extremely challenging. For this reason, the investigation of evolutionary responses of native species facing invasives may significantly benefit of extensive studies evaluating multiple traits and life stages, possibly also taking into account the time of coexistence (e.g., repeating experiments at diverse time points after the invasion).

Overall, morphological analyses are in agreement with the idea that, shortly after invasions, species responses to the new selective pressures mostly occur through plasticity (Sih et al. 2011), while local adaptation and canalization could have higher importance in the long term (Kiesecker and Blaustein 1997; Moore et al. 2004). The absence of any significant interaction between crayfish exposure and tadpole origin is in line with this prediction and, at present, provides few support for the canalization, or for the increased plasticity hypotheses for the traits we observed. Our study system remains excellent to test this hypothesis, as the same experiment can be repeated multiple times in the future, evaluating how each population evolves through time in response to invasive species.

Though the plastic morphological response of tadpoles suggests that the invasive crayfish is perceived as a threat, the mechanisms through which predator recognition occurred are less clear. During rearing, tadpoles were continuously exposed to both chemical and visual cues by the non-native predator. On the one hand, the capacity to exhibit anti-predator responses to these cues can be favoured when prey share a common evolutionary history with native predators showing a certain degree of similarity or phylogenetic proximity with the invasive one (Ferrari et al. 2007; Davis et al. 2012). For instance, in our study area $R$. latastei historically coexisted with the native white-clawed crayfish (Austropotamobius pallipes), which shares similar trophic niche and predatory habits with P. clarkii. On the other hand, observed plastic variation in $R$. lataste $i$ tadpoles can be the result of a general anti-predator response to large approaching or moving shapes (Mathis and Vincent 2000; Wilson et al. 2018) or to unfamiliar cues (Brown and Chivers 2005). Even if plastic shifts in tadpole morphology after crayfish exposure were evident, mechanisms allowing crayfish recognition need further investigation.

Behavioural traits are commonly considered highly plastic, as their modulation is generally faster, more reversible and less energetically demanding than morphological shifts (Schoeppner and Relyea 2005; Weis and Sol 2016). However, anti-predator behaviour often involves balancing trade-offs between escaping predation risk and devoting time to meet other fitness-related demands (e.g., foraging and mating; Lima and Dill 1990; Ferrari et al. 2009; Winandy and Denoël 2013). Predator avoidance and activity reduction are common anti-predator behaviours, but they are often associated to decreased foraging or exploitation of suboptimal trophic niches (Lima and Dill 1990). However, prey has to feed to grow and develop, thus activity reduction may be not sustainable over long-term. In fact, when predation risk is prolonged or constantly high, anti-predator responses can become weaker or be even suppressed to permit foraging and favour rapid growth (Turner 1997; Lima and Bednekoff 1999; Ferrari et al. 2009). In these cases, other anti-predator strategies, such as morphological and life-history modifications (e.g. defensive structures and faster development) can be favoured. In our study, the absence of behavioural responses, together with the expression of morphological traits facilitating escape from predators and tadpole relative increase in body size, matches this prediction. Thus, constant exposure to predation risk can have progressively reversed advantages of behavioural avoidance of predator (e.g., hiding or decrease activity) as the costs deriving from maintaining this behaviour rapidly outweighed its benefits. Instead, constant exposure to predator may have favoured differential resource allocation and the fostering of traits enhancing survival in case of predator encounter, such as an increase in tail muscle dimension or strategies limiting predator exposure, as rapid development (Melotto et al. 2020). The absence of 
behavioural shifts may also have occurred because tadpoles were not exposed to all the cues associated to predation risk. Aquatic prey rely on different suites of predation-related cues that play a key role in predator recognition and anti-predator responses, including alarm cues released by stressed or wounded conspecifics and foraging cues related to predator diet (Kats and Dill 1998; Schoeppner and Relyea 2005; Ferrari et al. 2010). These cues can facilitate prey risk assessment through learning, by mediating the association of predator kairomones perception with a potential threat, both with native and non-native predators (Marquis et al. 2004; Mandrillon and Saglio 2005; Gonzalo et al. 2007; Polo-Cavia and GomezMestre 2014). Predation cues (i.e., foraging and alarm cues) can be perceived by prey as signals of a transient peak in predation risk and thus often trigger short-term and reversible responses, such as behaviour (Van Buskirk and Arioli 2002; Schoeppner and Relyea 2005). Under natural conditions, the crayfish successfully preys on tadpoles, likely producing cues that may favour short-term behavioural responses. In our study predation cues were absent because of ethical reasons, and we cannot exclude this might have played a role in the lack of behavioural response. Nevertheless the broad responsiveness of tadpoles to crayfish cues in terms of both morphological and developmental traits (Melotto et al. 2020) indicates that its kairomones are perceived as a risk cue by $R$. latastei. Moreover, the observation of behavioural shifts in tadpoles of this frog after transient exposure to crayfish cues (Melotto et al., 2021), suggests that these stimuli are able to trigger anti-predator behaviours in this species.

Even though we observed significant plastic responses, it is unclear whether such responses consistently improve tadpole fitness and enhance their possibility to withstand biological invasions. Few studies have assessed the effectiveness of the crayfish-induced variation in native prey, and only rarely observed positive effects of plastic response on tadpole survival (Polo-Cavia and Gomez-Mestre 2014), while the decline of amphibian communities invaded by $P$. clarkii has been often observed (even in species with plastic responses, see e.g. Cruz et al. 2008; Ficetola et al. 2011; Nunes et al. 2013). Ethical issues and the threatened status of $R$. lataste $i$ hampered testing the adaptive values of the plastic shifts we observed (i.e., through predation trials), thus if these responses actually help frogs to withstand crayfish predation or not remains an open question. Even if invaded frog populations are not necessarily declining, the crayfish has been shown to reduce recruitment with complex effects on metapopulation dynamics, and such reduced recruitment could cause the broad-scale collapse of populations (Manenti et al. 2020; Falaschi et al. 2021). Assessing if morphological plasticity really increases fitness under natural conditions is particularly complex, because multiple abiotic and biotic factors act together in a contextdependent fashion (Blaustein and Kiesecker 2002; Kiesecker et al. 2002). Still understanding which responses can help long-term persistence of invaded populations is essential to predict the consequences of invasions across species and habitats, and to identify the conditions under which management actions are the priority, or are most likely to be successful.

\section{Conclusions}

Our study sheds new light on the key role played by phenotypic plasticity in allowing quick responses of native species facing the spreading of new predators. Tadpoles of a native frog altered their morphology during development when exposed to alien crayfish predator, while we observed limited evidence for adaptive divergence between invaded and uninvaded populations. However, whether these responses are actually effective in withstanding the alien predators or in fostering evolutionary changes remains to be tested; future studies should address these issues, also evaluating trait variation in invaded systems over time. Even if understanding the complex morphological and behavioural responses induced by predation risk can be extremely challenging, considering multiple traits is essential to assess predatorprey interactions between native and non-native species. As the response can be detectable only at one or few traits, focusing on one feature only can lead to underestimate the prey response to invasive predators. Integrated analyses, combining morphological and behavioural observations, prove to be necessary to unravel the complexity of responses to major global change stressors.

\section{Data availability statement}

The datasets generated during and/or analysed during the current study will be available in the fisgshare 
repository (https://doi.org/10.6084/m9.figshare. 15078429.v2).

Acknowledgements We are grateful to the all the students who actively participated to this study: A. Urso and S. Robino helped in tadpole rearing, morphological measurements and behavioural experiments; S. Demicheli and L. Bini performed video analyses. The staff of the Acquario Civico di Milano kindly allowed the use of Aquarium facilities; E. Lo Parrino, S. Pitton, S. Romagnoli and B. Barzaghi participated to sampling.

Author contribution A.M., G.F.F. and R.M. designed the experiments, performed samplings, analysed the data and wrote the manuscript; A.M. reared the animals and performed the experiments; N.A. provided assistance with animal rearing and revised the manuscript; R.P. participated in conceiving the experiment and revised the manuscript.

Funding Open access funding provided by Università degli Studi di Milano within the CRUI-CARE Agreement.

\section{Declarations}

Competing interests The authors declare that they have no competing interests.

Open Access This article is licensed under a Creative Commons Attribution 4.0 International License, which permits use, sharing, adaptation, distribution and reproduction in any medium or format, as long as you give appropriate credit to the original author(s) and the source, provide a link to the Creative Commons licence, and indicate if changes were made. The images or other third party material in this article are included in the article's Creative Commons licence, unless indicated otherwise in a credit line to the material. If material is not included in the article's Creative Commons licence and your intended use is not permitted by statutory regulation or exceeds the permitted use, you will need to obtain permission directly from the copyright holder. To view a copy of this licence, visit http://creativecommons.org/licenses/by/4.0/.

\section{References}

Bellard C, Cassey P, Blackburn TM (2016) Alien species as a driver of recent extinctions. Biol Let 12:20150623

Blaustein AR, Kiesecker JM (2002) Complexity in conservation: lessons from the global decline of amphibian populations. Ecol Lett 5:597-608

Bosch J, Sanchez-Tomé E, Fernández-Loras A, Oliver JA, Fisher MC, Garner TW (2015) Successful elimination of a lethal wildlife infectious disease in nature. Biol Let 11:20150874

Brown GE, Chivers DP (2005) Learning as an adaptive response to predation. P.C.I Barbosa (Eds) Ecology of Predator-Prey Interactions, Oxford Univ Press, New York
Bytheway JP, Banks PB (2019) Overcoming prey naiveté: Freeliving marsupials develop recognition and effective behavioral responses to alien predators in Australia. Glob Change Biol 25:1685-1695

Carthey AJ, Blumstein DT (2018) Predicting predator recognition in a changing world. Trends Ecol Evol 33:106-115

Cattau CE, Fletcher RJ Jr, Kimball RT, Miller CW, Kitchens WM (2018) Rapid morphological change of a top predator with the invasion of a novel prey. Nature Ecology \& Evolution 2:108

Chevin LM, Lande R (2010) When do adaptive plasticity and genetic evolution prevent extinction of a density-regulated population Evolution. Int J Org Evol 64:1143-1150

Clavero M, Garcia-Berthou E (2005) Invasive species are a leading cause of animal extinctions. Trends Ecol Evol 20:110-110

Cox JG, Lima SL (2006) Naiveté and an aquatic-terrestrial dichotomy in the effects of introduced predators. Trends Ecol Evol 21:674-680

Crispo E (2008) Modifying effects of phenotypic plasticity on interactions among natural selection, adaptation and gene flow. J Evol Biol 21:1460-1469

Crispo E, Chapman L (2010) Geographic variation in phenotypic plasticity in response to dissolved oxygen in an African cichlid fish. J Evol Biol 23:2091-2103

Cruz M, Segurado P, Sousa M, Rebelo R (2008) Collapse of the amphibian community of the Paul do Boquilobo Natural Reserve (central Portugal) after the arrival of the exotic American crayfish Procambarus clarkii. The Herpetological Journal 18:197-204

Davis DR, Epp KJ, Gabor CR (2012) Predator generalization decreases the effect of introduced predators in the san marcos salamander, Eurycea nana. Ethology 118:1191-1197

Dayton GH, Saenz D, Baum KA, Langerhans RB, DeWitt TJ (2005) Body shape, burst speed and escape behavior of larval anurans. Oikos 111:582-591

Falaschi M, Manenti R, Thuiller W, Ficetola GF (2019) Continental-scale determinants of population trends in European amphibians and reptiles. Glob Change Biol 25:3504-3515

Falaschi M, Melotto A, Manenti R, Ficetola GF (2020) Invasive Species and Amphibian Conservation. Herpetologica.

Falaschi M, Giachello S, Parrino EL, Muraro M, Manenti R, Ficetola GF (2021) Long-term drivers of persistence and colonization dynamics in spatially structured amphibian populations. Conservation Biology.

Ferrari MCO, Gonzalo A, Messier F, Chivers DP (2007) Generalization of learned predator recognition: an experimental test and framework for future studies. Proc Royal Soc B-Biol Sci 274:1853-1859

Ferrari MCO, Sih A, Chivers DP (2009) The paradox of risk allocation: a review and prospectus. Anim Behav 78:579-585

Ferrari MCO, Wisenden BD, Chivers DP (2010) Chemical ecology of predator-prey interactions in aquatic ecosystems: a review and prospectus. Can J Zool 88:698-724

Ficetola GF, De Bernardi F (2005) Supplementation or in situ conservation? Evidence of local adaptation in the Italian agile frog Rana latastei and consequences for the management of populations. Anim Conserv 8:33-40 
Ficetola GF, Garner TW, De Bernardi F (2007) Genetic diversity, but not hatching success, is jointly affected by postglacial colonization and isolation in the threatened frog, Rana latastei. Mol Ecol 16:1787-1797

Ficetola F, Gentile ME, Siesa R, Manenti L, Bottoni FD, Bernardi F, Padoa-Schioppa E (2011) Early assessment of the impact of alien species: differential consequences of an invasive crayfish on adult and larval amphibians. Divers Distrib 17:1141-1151

Field A, Miles J, Field Z (2012) Discovering statistics using R. Sage publications.

Frankham R, Ballou JD, Briscoe DA (2004) A primer of conservation genetics. Cambridge University Press

Garner TW, Pearman PB, Angelone S (2004) Genetic diversity across a vertebrate species' range: a test of the centralperipheral hypothesis. Mol Ecol 13:1047-1053

Ghalambor CK, McKay JK, Carroll SP, Reznick DN (2007) Adaptive versus non-adaptive phenotypic plasticity and the potential for contemporary adaptation in new environments. Funct Ecol 21:394-407

Gherardi F (2006) Crayfish invading Europe: the case study of Procambarus clarkii. Mar Freshw Behav Physiol 39:175-191

Gherardi F, Barbaresi S, Salvi G (2000) Spatial and temporal patterns in the movement of Procambarus clarkii, an invasive crayfish. Aquat Sci 62:179-193

Gomez-Mestre I, Díaz-Paniagua C (2011) Invasive predatory crayfish do not trigger inducible defences in tadpoles. Proc Royal Soc B: Biol Sci 278:3364-3370

Gonzalo A, Lopez P, Martin J (2007) Iberian green frog tadpoles may learn to recognize novel predators from chemical alarm cues of conspecifics. Anim Behav 74:447-453

Gosner KL (1960) A simplified table for staging anuran embryos and larvae with notes on identification. Herpetologica 16:183-190

Guarino FM, Mazzotti S (2001) Longevity and age at sexual maturity in Rana latastei (Amphibia, Anura) by skeletochronology. In: Crete PLENHMO (Eds). Herpetologia Candiana, Irakleio. pp 83-88

Hossie T, Landolt K, Murray DL (2017) Determinants and coexpression of anti-predator responses in amphibian tadpoles: a meta-analysis. Oikos 126:173-184

Johnson MT, Munshi-South J (2017) Evolution of life in urban environments. Science 358:eaam8327

Jussila J, Toljamo A, Makkonen J, Kukkonen H, Kokko H (2014) Practical disinfection chemicals for fishing and crayfishing gear against crayfish plague transfer. Knowl Manag Aquatic Ecosyst. 02.

Kaplan R (1998) Maternal effects, developmental plasticity, and life history evolution Maternal effects as adaptations. Oxford University Press, p England

Kats LB, Dill LM (1998) The scent of death: chemosensory assessment of predation risk by prey animals. Ecoscience 5:361-394

Kats LB, Ferrer RP (2003) Alien predators and amphibian declines: review of two decades of science and the transition to conservation. Divers Distrib 9:99-110

Kiesecker JM, Blaustein AR (1997) Population differences in responses of red-legged frogs (Rana aurora) to introduced bullfrogs. Ecology 78:1752-1760
Kiesecker JM, Chivers DP, Anderson M, Blaustein AR (2002) Effect of predator diet on life history shifts of red-legged frogs, Rana aurora. J Chem Ecol 28:1007-1015

Kishida O, Trussell GC, Nishimura K (2009) Top-down effects on antagonistic inducible defense and offense. Ecology 90:1217-1226

Kishida O, Trussell GC, Mougi A, Nishimura K (2010) Evolutionary ecology of inducible morphological plasticity in predator-prey interaction: toward the practical links with population ecology. Popul Ecol 52:37-46

Lande R (2009) Adaptation to an extraordinary environment by evolution of phenotypic plasticity and genetic assimilation. J Evol Biol 22:1435-1446

Langkilde T (2009) Invasive fire ants alter behavior and morphology of native lizards. Ecology 90:208-217

Leung C, Rescan M, Grulois D, Chevin LM (2020) Reduced phenotypic plasticity evolves in less predictable environments. Ecol Lett 23:1664-1672

Levis NA, Pfennig DW (2019) Phenotypic plasticity, canalization, and the origins of novelty: evidence and mechanisms from amphibians. Seminars Cell Dev Biol 88:80-90

Levis NA, Isdaner AJ, Pfennig DW (2018) Morphological novelty emerges from pre-existing phenotypic plasticity. Nature Ecology \& Evolution 2:1289-1297

Lima SL, Bednekoff PA (1999) Temporal variation in danger drives antipredator behavior: the predation risk allocation hypothesis. Am Nat 153:649-659

Lima SL, Dill LM (1990) Behavioral decisions made under the risk of predation - a review and prospectus. Can J Zool 68:619-640

Lo Parrino E, Ficetola GF, Manenti R, Falaschi M (2020) Thirty years of invasion: the distribution of the invasive crayfish Procambarus clarkii in Italy. Biogeographia 35:43-50

Mandrillon A-L, Saglio P (2005) Prior exposure to conspecific chemical cues affects predator recognition in larval common toad (Bufo bufo). Arch Hydrobiol 164:1-12

Manenti R, Denoel M, Ficetola GF (2013) Foraging plasticity favours adaptation to new habitats in fire salamanders. Anim Behav 86:375-382

Manenti R, Bonelli M, Scaccini D, Binda A, Zugnoni A (2014) Austropotamobius pallipes reduction vs. Procambarus clarkii spreading: management implications. J Nat Conserv 22:586-591

Manenti R, Falaschi M, Delle Monache D, Marta S, Ficetola F (2020) Network-scale effects of invasive species on spatially-structured amphibian populations. Ecography 43:119-127

Marquis O, Saglio P, Neveu A (2004) Effects of predators and conspecific chemical cues on the swimming activity of Rana temporaria and Bufo bufo tadpoles. Arch Hydrobiol 160:153-170

Mathis A, Vincent F (2000) Differential use of visual and chemical cues in predator recognition and threat-sensitive predator-avoidance responses by larval newts (Notophthalmus viridescens). Can J Zool 78:1646-1652

Melotto A, Ficetola GF, Manenti R (2019) Safe as a cave? Intraspecific aggressiveness rises in predator-devoid and resource-depleted environments. Behav Ecol Sociobiol $73: 68$ 
Melotto A, Manenti R, Ficetola GF (2020) Rapid adaptation to invasive predators overwhelms natural gradients of intraspecific variation. Nat Commun 11:1-10

Melotto A, Ficetola GF, Pennati R, Ancona N, Manenti R (2021) Visual recognition and coevolutionary history drive responses of amphibians to an invasive predator. Behav Ecol

Mooney HA, Cleland EE (2001) The evolutionary impact of invasive species. Proc Natl Acad Sci 98:5446-5451

Moore RD, Griffiths RA, O’Brien CM, Murphy A, Jay D (2004) Induced defences in an endangered amphibian in response to an introduced snake predator. Oecologia 141:139-147

Nentwig W, Bacher S, Kumschick S, Pyšek P, Vilà M (2018) More than "100 worst" alien species in Europe. Biol Invasions 20:1611-1621

Noble DW, Radersma R, Uller T (2019) Plastic responses to novel environments are biased towards phenotype dimensions with high additive genetic variation. Proc Natl Acad Sci 116:13452-13461

Nunes AL, Richter-Boix A, Laurila A, Rebelo R (2013) Do anuran larvae respond behaviourally to chemical cues from an invasive crayfish predator? A community-wide study. Oecologia 171:115-127

Nunes AL, Orizaola G, Laurila A, Rebelo R (2014a) Morphological and life-history responses of anurans to predation by an invasive crayfish: An integrative approach. Ecol Evol 4:1491-1503

Nunes AL, Orizaola G, Laurila A, Rebelo R (2014b) Rapid evolution of constitutive and inducible defenses against an invasive predator. Ecology 95:1520-1530

Nunes AL, Fill JM, Davies SJ, Louw M, Rebelo AD, Thorp CJ, Vimercati G, Measey J (2019) A global meta-analysis of the ecological impacts of alien species on native amphibians. Proc R Soc B 286:20182528

Pease KM, Wayne RK (2014) Divergent responses of exposed and naive Pacific tree frog tadpoles to invasive predatory crayfish. Oecologia 174:241-252

Pérez-Escudero A, Vicente-Page J, Hinz RC, Arganda S, De Polavieja GG (2014) idTracker: tracking individuals in a group by automatic identification of unmarked animals. Nat Methods 11:743

Phillips BL, Shine R (2006) An invasive species induces rapid adaptive change in a native predator: cane toads and black snakes in Australia. Proc Royal Soc B-Biol Sci 273:1545-1550

Pigliucci M (2001) Phenotypic plasticity: beyond nature and nurture. JHU Press, Baltimore

Pigliucci M, Murren CJ, Schlichting CD (2006) Phenotypic plasticity and evolution by genetic assimilation. J Exp Biol 209:2362-2367

Polo-Cavia N, Gomez-Mestre I (2014) Learned recognition of introduced predators determines survival of tadpole prey. Funct Ecol 28:432-439

R C. T. (2019) R: A language and environment for statistical computing. R Foundation for Statistical Computing.

Reger J, Lind MI, Robinson MR, Beckerman AP (2018) Predation drives local adaptation of phenotypic plasticity. Nat Ecol Evol 2:100

Rehage JS, Dunlop KL, Loftus WF (2009) Antipredator responses by native mosquitofish to non-native cichlids: an examination of the role of prey naiveté. Ethology 115:1046-1056

Relyea RA (2001) Morphological and behavioral plasticity of larval anurans in response to different predators. Ecology 82:523-540

Relyea RA (2003) Predators come and predators go: the reversibility of predator-induced traits. Ecology 84:1840-1848

Relyea RA (2007) Getting out alive: how predators affect the decision to metamorphose. Oecologia 152:389-400

Rodríguez C, Bécares E, Fernández-Aláez M, Fernández-Aláez C (2005) Loss of diversity and degradation of wetlands as a result of introducing exotic crayfish. Biol Invasions 7:75

Salo P, Korpimäki E, Banks PB, Nordström M, Dickman CR (2007) Alien predators are more dangerous than native predators to prey populations. Proc Royal Soc B: Biol Sci 274:1237-1243

Saura-Mas S, Benejam L (2019) Effects of the invasive crayfish Procambarus clarkii on growth and development of Pelophylax perezi tadpoles in field conditions. Anim Biodivers Conserv 42:245-252

Schneider CA, Rasband WS, Eliceiri KW (2012) NIH Image to ImageJ: 25 years of image analysis. Nat Methods 9:671

Schoeppner NM, Relyea RA (2005) Damage, digestion, and defence: the roles of alarm cues and kairomones for inducing prey defences. Ecol Lett 8:505-512

Scribano G, Balestrieri A, Gazzola A, Pellitteri-Rosa D (2020) Strong behavioural defensive responses of endemic Rana latastei tadpoles induced by a native predator's odour. Ethology 126:922-930

Sih A, Bolnick DI, Luttbeg B, Orrock JL, Peacor SD, Pintor LM, Preisser E, Rehage JS, Vonesh JR (2010) Predator-prey naïveté, antipredator behavior, and the ecology of predator invasions. Oikos 119:610-621

Sih A, Ferrari MC, Harris DJ (2011) Evolution and behavioural responses to human-induced rapid environmental change. Evol Appl 4:367-387

Sillero N, Campos J, Bonardi A, Corti C, Creemers R, Crochet P-A, Isailović JC, Denoël M, Ficetola GF, Gonçalves J (2014) Updated distribution and biogeography of amphibians and reptiles of Europe. Amphibia-Reptilia 35:1-31

Sindaco R, Romano A, Andreone F, Garner TWJ, Schmidt B, Corti C, Vogrin M (2009) Rana latastei, In The IUCN red list of threatened species. In IUCN, editor.

Smith GR, Boyd A, Dayer CB, Winter KE (2008) Behavioral responses of American toad and bullfrog tadpoles to the presence of cues from the invasive fish, Gambusia affinis. Biol Invasions 10:743-748

Stamp MA, Hadfield JD (2020) The relative importance of plasticity versus genetic differentiation in explaining between population differences; a meta-analysis. Ecol Lett 23:1432-1441

Thawley CJ, Goldy-Brown M, McCormick GL, Graham SP, Langkilde $\mathrm{T}$ (2019) Presence of an invasive species reverses latitudinal clines of multiple traits in a native species. Glob Change Biol 25:620-628

Turner AM (1997) Contrasting short-term and long-term effects of predation risk on consumer habitat use and resources. Behav Ecol 8:120-125 
Van Buskirk J (2002) A comparative test of the adaptive plasticity hypothesis: relationships between habitat and phenotype in anuran larvae. Am Nat 160:87-102

Van Buskirk J (2009) Natural variation in morphology of larval amphibians: phenotypic plasticity in nature? Ecol Monogr 79:681-705

Van Buskirk J (2017) Spatially heterogeneous selection in nature favors phenotypic plasticity in anuran larvae. Evolution 71:1670-1685

Van Buskirk J, Arioli M (2002) Dosage response of an induced defense: how sensitive are tadpoles to predation risk? Ecology 83:1580-1585

Warkentin KM (2011) Plasticity of hatching in amphibians: evolution, trade-offs, cues and mechanisms. Integr Comp Biol 51:111-127

Weis JS, Sol D (2016) Biological invasions and animal behaviour. Cambridge University Press
Wells KD (2007) The ecology and behavior of amphibians. University of Chicago Press, Chicago

West-Eberhard MJ (2003) Developmental plasticity and evolution. Oxford University Press

Wilson EA, Dudley TL, Briggs CJ (2018) Shared behavioral responses and predation risk of anuran larvae and adults exposed to a novel predator. Biol Invasions 20:475-485

Winandy L, Denoël M (2013) Introduced goldfish affect amphibians through inhibition of sexual behaviour in risky habitats: an experimental approach. PLoS ONE 8:e82736

Publisher's Note Springer Nature remains neutral with regard to jurisdictional claims in published maps and institutional affiliations. 